\title{
An evaluation of three-dimensional facial changes after surgically assisted rapid maxillary expansion (SARME)
}

\section{Jurij Zupan}

Univerza v Ljubljani Medicinska Fakulteta

Nataša Ihan Hren

Univerza v Ljubljani Medicinska Fakulteta

Miha Verdenik ( $\nabla$ miha.verdenik@gmail.com )

University Medical Centre Ljubljana https://orcid.org/0000-0001-6545-9785

Research article

Keywords: SARME, three-dimensional (3D), facial convexity, Maxillary transverse deficiency (MTD)

Posted Date: February 26th, 2021

DOI: https://doi.org/10.21203/rs.3.rs-268134/v1

License: (c) (i) This work is licensed under a Creative Commons Attribution 4.0 International License.

Read Full License 


\section{Abstract}

Background: The purpose of the study was to evaluate the three-dimensional (3D) facial changes following surgically assisted rapid maxillary expansion (SARME). In 15 skeletally mature patients with maxillary transverse deficiency the planned maxillary expansion (on average $8.8 \mathrm{~mm} \pm 2.3 \mathrm{~mm}$ ) was achieved with bone-borne palatal distractor. The 3D optical scans of the facial surface were obtained before and 6 months after SARME and compared with cephalometric and regional analysis to evaluate the soft-tissue changes.

Findings. The largest differences between the pre- and post-operation scans were observed for the paranasal and cheek area $(1.4 \pm 1.0 \mathrm{~mm})$ in the lateral direction with a soft-to-hard tissue ratio of 0.22 . Significant differences occurred for an increased nasal width, a decreased upper-face height with an unchanged lower height, an increased vertical philtrum height and an increased nasolabial angle. A significant increase in the facial profile angle was also observed, resulting in an increased facial convexity and anterior displacement of the upper-lip area.

Conclusions. We have confirmed the widening of the nose and increased projection in the cheek and paranasal area in the lateral direction after maxillary expansion, while we found facial convexity increases, reflecting the underlying advancement of the maxilla.

\section{Introduction}

Maxillary transverse deficiency (MTD) affects both the function and the appearance of the patient's orofacial region (1). It can be isolated or combined with other sagittal or vertical dento-facial deformities that clinically mask the anomalies in the transverse dimension(2). The abnormal facial features in MTD are minimal and limited to a deficiency of the middle facial third, narrow nares and nasal base, and deepened nasolabial folds (1). However, an intra-oral examination can reveal a uni- or bilateral posterior cross bite, dental crowding and a narrow and high palatal vault (1). These abnormalities can also be associated with functional impairments $(3,4)$.

The transverse expansion of the narrow maxilla by opening the mid-palatal suture was first reported by Angell (5) and rapid maxillary expansion is nowadays a generally accepted method in growing individuals. After the ossification of the mid-palatal suture, which is reported to happen during adolescence (14-15 years of age, (6), until the end of adolescence at 18 years of age, (7) or even later (8), managing severe MTD requires a correction with surgery. Surgically assisted rapid maxillary expansion (SARME), which combines orthodontics and surgical procedures, is now a widely used procedure for the correction of severe MTD in skeletally mature patients.

Various studies have evaluated immediate and long-term dental, skeletal, periodontal, nasal airway, and facial soft-tissue changes following SARME. 3D imaging modalities, such as cone-beam computed tomography or stereometric surface imaging, are rapidly replacing conventional 2D technologies (9). The most obvious effects of SARME are widening of the maxillary dental arch and expansion of the maxillary 
and palatal structures in the transverse plane (9). Facial changes following SARME reflect the underlying dento-skeletal movements. The most frequently reported findings are widening of the nose and an increased projection of the cheek area in the lateral direction (9). A slight retro-positioning of the upper lip (10) and an anterio-inferior displacement of the whole naso-maxillary complex after SARME were also reported (11).

SARME has a well-known effect on the facial skeletal framework and, consequently, affects the facial aesthetic, which should be considered during diagnostics, treatment planning and evaluation. Previous studies evaluating soft-tissue changes after SARME focused mostly on the facial areas where the underlying bones had been expanded.(10-14) There are also some contradictions about the sagittal facial response after SARME. Therefore, we decided to use 3D facial imaging to assess the facial changes, including sagittal changes after SARME, and to evaluate the soft-to-hard tissue ratios for maxillary expansion.

\section{Materials And Methods}

A sample of 15 patients (8 females, 7 males) with an MTD greater than $7 \mathrm{~mm}$ were included in the study. The median age of the patients at the time of the surgery was $26.0 \pm 9.0$ years. Each patient's protocol included information about their sex, age, height, body mass and maxillary transverse deficiency. The severity of the deformity was defined using dental study casts and measuring the transversal dimension at the level of the canine and first molar teeth and comparing this to the lower arch. The amount of needed trans-palatal expansion was calculated as an average of the two measured transverse discrepancy levels, and it was found to be $8.8( \pm 2.3)$ millimetres. This study was approved by the XXX National Medical Ethics Committee (conformation number 0120-303/2017) and in compliance with the Helsinki Declaration. All the patients also signed informed consent.

All the patients were operated on by the same surgeon using the same technique. Under general anaesthesia, subtotal LeFort I osteotomy was performed with an additional median osteotomy of the maxilla and the palate. Osteotomy lines were carried out as in regular LeFort I with complete disjunction in the pterygo-maxillary fissure; the only difference was leaving the posterior aspect of the lateral nasal wall intact. A bone-borne palatal distractor was activated after 1 week with a daily distraction of 0.33 $\mathrm{mm}$. When the required expansion was achieved, the distractor was kept in place for 4 months as a rigid retention. An active orthodontic treatment with a fixed appliance was initiated 8-10 weeks after the expansion to eliminate the diastemas, align the dental arch, and achieve a good occlusion.

In addition to the standard diagnostics, two 3D facial surface scans of each patient were obtained. A preoperative 3D image was taken on the day of the operation and the second image, 6 months after the operation at the end of the retention period. During facial imaging with a 3D optical scanner (Artec) the patient was sitting comfortably in the upright position with his/her head in the natural position. The 3D facial images were imported into RapidForm 2006 (INUS Technology, Inc.) computer software. 37 3D anatomical landmarks were identified on the facial surface of each image (Fig. 1). Using the coordinates 
$(x, y, z)$ of these landmarks we were able to calculate the linear distance between the points and measure the angles. Various facial parameters in the transverse and vertical directions and also the angles were chosen to anthropometrically (cephalometric analysis of the 3D facial scan) analyse the facial morphology.

A facial surface-areas comparison was additionally conducted. Both 3D scans of each patient were digitally registered in the same workplace using the regional best-fit method. The forehead, supraorbital and nasal root regions were selected for the superimposition. Four vertical and four horizontal planes were used to divide the facial surface into 17 areas (Fig. 2). A software tool was then able to calculate the average difference in the displacement between both 3D images in each region (shell-to-shell difference) corresponding to the soft-tissue changes following the treatment.

All the acquired data from the anthropometric facial analysis and the facial surface-areas comparison were imported to Microsoft Excel and IBM SPSS Statistics for statistical analyses. The pre- and postexpansion facial parameters were compared with the paired t-test. The significance level was set at $p<$ 0.05. A multivariate linear-regression model was later used to correlate the maxillary expansion width to the soft-tissue changes found in the observed regions. Because the changes on the left- and right-hand sides of the face showed similar values, we merged them and compared them as a common lateral area.

\section{Results}

An anthropometric (3D cephalometric) analysis was performed on the facial images before and after the maxillary expansion and the results were compared (Table 1). In the cephalometric analysis, significant differences occurred for an increased nasal width (at the level of the nasal ala for $1.1 \mathrm{~mm}$ and the nasal base for $2.2 \mathrm{~mm}$ ), a decreased upper-face height (for $1.4 \mathrm{~mm}$ ) with an unchanged lower height, an increased vertical philtrum height (for $0.8 \mathrm{~mm}$ ) and an increased nasolabial angle (for almost 3 degrees). A significant increase in the facial profile angle was also observed, resulting in an increased facial convexity and anterior displacement of the upper lip area. 
Table 1

Anthropometric analysis results showing the values of the observed parameters before and after the operation, their differences and their comparison with the t-test. The statistically significant differences are marked with an *.

\begin{tabular}{|lllll|}
\hline Parameter & Before & After & Diff. & Sig. \\
\hline inner eye distance | enL-enR $(\mathrm{mm})$ & $32.5 \pm 3.3$ & $32.5 \pm 2.9$ & $0.0 \pm 1.3$ & 0.962 \\
\hline nasal ala width | alL-alR $(\mathrm{mm})$ & $35.0 \pm 1.9$ & $36.2 \pm 2.2$ & $-1.1 \pm 1.7$ & $0.019^{\star}$ \\
\hline nasal base width | acL-acR $(\mathrm{mm})$ & $33.4 \pm 2.1$ & $35.6 \pm 2.4$ & $-2.2 \pm 1.7$ & $<.001^{\star}$ \\
\hline facial width | zyL-zyR $(\mathrm{mm})$ & $135 \pm 7.0$ & $134.0 \pm 6.0$ & $0.7 \pm 2.8$ & 0.380 \\
\hline gonion width | goL-goR $(\mathrm{mm})$ & $126 \pm 6.0$ & $125.0 \pm 6.0$ & $1.3 \pm 2.8$ & 0.095 \\
\hline mouth width | chL-chR $(\mathrm{mm})$ & $48.2 \pm 5.6$ & $48.5 \pm 5.1$ & $-0.2 \pm 2.8$ & 0.758 \\
\hline intermental width | meL-meR $(\mathrm{mm})$ & $57.1 \pm 4.7$ & $56.2 \pm 4.3$ & $0.9 \pm 4.4$ & 0.454 \\
\hline face height | g-pg $(\mathrm{mm})$ & $130.0 \pm 9.0$ & $129.0 \pm 10.0$ & $1.4 \pm 2.9$ & 0.082 \\
\hline upper face height | g-sn $(\mathrm{mm})$ & $72.4 \pm 5.0$ & $71.0 \pm 5.0$ & $1.4 \pm 1.7$ & $0.006^{\star}$ \\
\hline lower face height | sn-pg $(\mathrm{mm})$ & $58.9 \pm 6.7$ & $59.0 \pm 7.0$ & $-0.1 \pm 3.1$ & 0.857 \\
\hline nasal dorsum length | n-prn $(\mathrm{mm})$ & $50.7 \pm 4.9$ & $50.5 \pm 4.3$ & $0.2 \pm 1.6$ & 0.688 \\
\hline nasal tip protrusion | prn-sn $(\mathrm{mm})$ & $23.1 \pm 1.9$ & $22.5 \pm 2.2$ & $0.6 \pm 1.3$ & 0.092 \\
\hline prn-pg (mm) & $76.6 \pm 7.3$ & $76.4 \pm 7.5$ & $0.2 \pm 2.7$ & 0.802 \\
\hline vertical philtrum height | sn-st $(\mathrm{mm})$ & $21.6 \pm 2.7$ & $22.4 \pm 2.9$ & $-0.8 \pm 1.2$ & $0.025^{\star}$ \\
\hline facial profile angle | n-sn-pg $\left(^{\circ}\right)$ & $193.0 \pm 8.0$ & $195.0 \pm 8.0$ & $-1.7 \pm 2.7$ & $0.032^{\star}$ \\
\hline nasolabial angle | cm-sn-ls $\left(^{\circ}\right)$ & $111.0 \pm 7.0$ & $114.0 \pm 7.0$ & $-2.9 \pm 3.9$ & $0.013^{*}$ \\
\hline nasal width angle | acL-prn-acR $\left(^{\circ}\right)$ & $57.9 \pm 4.7$ & $64.2 \pm 7.0$ & $-6.3 \pm 4.9$ & $<.001^{\star}$ \\
\hline
\end{tabular}

To include all the surfaces and the data of the 3D image a shell-to-shell comparison was performed, presented with a color histogram in Fig. 2. Figure 3 presents the average distance between the pre- and post-operative scans in the selected areas and the results are presented in Table 2 . The greatest differences in the displacements between the pre- and post-operation scans were observed for the paranasal and cheek area $(1.4 \pm 1.0 \mathrm{~mm})$ in the lateral direction. 
Table 2

Average distances between pre- and post-operative scans in different facial areas

(Fig. 3) presented as the mean values (together with one standard deviation) in selected regions.

\begin{tabular}{|llllll|}
\hline \multicolumn{7}{|c|}{ Average distance [mm] } & & & \\
\hline Region & Right lateral & Right medial & Middle & Left medial & Left lateral \\
\hline 2 & $-0.2 \pm 0.9$ & $0.7 \pm 0.9$ & $0.2 \pm 0.8$ & $0.8 \pm 0.9$ & $-0.2 \pm 0.9$ \\
\hline 3 & $-0.4 \pm 0.9$ & $1.2 \pm 1.0$ & $0.4 \pm 1.0$ & $1.4 \pm 1.0$ & $-0.2 \pm 0.9$ \\
\hline 4 & $-0.6 \pm 0.5$ & $-0.5 \pm 1.0$ & $-0.1 \pm 0.9$ & $-0.2 \pm 0.8$ & $-0.2 \pm 0.5$ \\
\hline
\end{tabular}

The soft-to-hard tissue ratio was used to correlate the soft-tissue changes with underlying bone movements. The results of the linear-regression model did not show any statistically significant correlations between the amount of the maxillary expansion and the observed soft-tissue changes. When changes in a specific facial area were compared to the expansion the highest coefficient values were observed in areas $3 \mathrm{C}(0.41)$ and $3 \mathrm{M}(0.22)$.

\section{Discussion}

Due to good orthodontic primary care there is only limited number of patients referred for SARME, so our sample is limited, but with some caution the results are significant and led us to some conclusions. 3D imaging with stereometric surface scanners is a frequently used method for a facial soft-tissue evaluation in orthognathic surgery with an already-proven high level of accuracy and reliability (15). The linear-regression model did not manage to obtain any significant results, probably because of the relatively small variance in the maxillary expansion width, and, especially, because of the smaller sample.

The anthropometric analysis of the pre- and post-expansion 3D facial scans demonstrated a statistically significant widening of the nose after expansion at the level of the nasal ala $(+1.1 \mathrm{~mm})$ and the nasal base $(+2.2 \mathrm{~mm})$. The consequence of a wider nasal base was a statistically significant increase in the nasal width angle (AcR-Prn-AcL). The width of the mouth remained almost unchanged. It is primarily determined by the orbicularis oris muscle, which lacks the direct origin or insertion with a bony jaw. This could be the reason why the SARME do not seem to have a significant influence on the width of the mouth.

The vertical dimension demonstrated two significant changes. The upper-face-height parameter significantly decreased, indicating the sub-nasale landmark, and the surrounding tissues moved in the superior direction (towards the glabella landmark), while the lower-face height remained unchanged. This superior positioning of the sub-nasale is probably one of the consequences of the complex effect SARME has on the nose morphology, including widening. Conflicting findings were reported by Lagravere and colleagues (16), who concluded that vertical and sagittal skeletal changes following SARME or not clinically significant. The lower-face height remained unchanged, which suggests that no mandibular 
rotation occurs. In a study by Tong and colleagues (17) a displacement of the chin (pogonion) in a posterior and inferior direction was demonstrated, suggesting the clockwise rotation of the mandible. Also, Oliveira and colleagues (18) reported in their study using CBCT (cone beam computer tomography) scans that a clockwise rotation of the mandible is a transient effect immediately after SARME, but tends to return close to the initial values 6 months after expansion. Secondly, the vertical philtrum height significantly increased, as a result of superior positioning of the sub-nasale area. Contradictory findings were reported by Alves and colleagues (19), who concluded that nasal length and projection and upper-lip length (philtrum height in our study) were not altered by SARME.

A significant increase in the soft-tissue facial profile angle also demonstrates changes in the sagittal direction after SARME. Since the expansion occurs in the middle third of the face, it is clear that anterior repositioning of the sub-nasale landmark occurs. The analysis indeed demonstrated anterior positioning of this area (3C, upper lip area). The facial profile after SARME has, therefore, increased convexity. This is important to consider in treatment planning since some MTD patients also exhibit simultaneous sagittal dento-facial deformity, such as skeletal Class II or III (1). These findings suggest that SARME tends to improve the skeletal Class III malocclusion and worsen the skeletal Class II. Our results contradict the results of Nada and colleagues (10), who found slight retro-positioning of the central part of the upper lip in both groups. Even though our method of 3D facial surface imaging cannot assess bone movements directly, we can still presume that some degree of maxillary advancement occurs following SARME in our patients. This difference could be attributed to the surgical technique, since the posterior part of the lateral nasal wall remained intact in our subjects. Therefore, the forces of the trans-palatinal distractor, besides the transversal expansion, probably move the maxilla slightly anteriorly. Another important sagittal effect that we encountered was a significant increase in the nasolabial angle.

Regional analysis (Fig. 3) showed the small changes after SARME over the whole face. They are the largest immediately over the expanded areas, but also occur in the lower third of the face, below the lower jaw and in posterior parts of the face. It seems that widening of the soft tissues over expanded areas consequently narrows the posterior and lower parts of the face. We observed that the facial soft-tissue mask acts as one unit, as already reported in other orthognathic procedures (20).

Our study objectively evaluates facial changes following SARME in all three dimensions. However, not only do some of our results differ from those of other studies, but the methodology and 3D observation of the whole face also seem to be different. We have confirmed some of the already-known facts, such as widening of the nose and increased projection in the cheek. On the other hand, an increased facial convexity after expansion is a new finding, reflecting the underlying advancement of the maxilla. Furthermore, we observed a reduced upper-face height, while the lower height remained unaffected.

\section{LIST OF ABBREVIATIONS}

3D - three-dimensional

SARME - surgically assisted rapid maxillary expansion 
MTD - maxillary transverse deficiency

CBCT - cone beam computer tomography

\section{Declarations}

\section{ETHICAL APPROVAL AND CONSENT TO PARTICIPATE}

This study was approved by the Slovenian National Medical Ethics Committee (conformation number 0120-303/2017) and in compliance with the Helsinki Declaration. All the patients also signed informed consent.

\section{CONSENT FOR PUBLICATION}

Not applicable.

\section{AVAILABILITY OF DATA AND MATERIALS}

The datasets used and/or analysed during the current study are available from the corresponding author on reasonable request.

\section{COMPETING INTEREST}

The authors declare that they have no competing interests.

\section{FUNDING}

This research did not receive any specific grant from funding agencies in the public, commercial, or notfor-profit sectors.

\section{AUTHORS CONTRIBUTION}

Jurij Zupan: Formal analysis, Resources, Writing - Original Draft

Nataša Ihan Hren: Conceptualization, Methodology, Visualization, Supervision, Project administration Miha Verdenik: Conceptualization, Software, Validation, Writing - Review \& Editing, Supervision

\section{ACKNOWLEDGEMENTS}

Thanks to Paul John McGuiness for his proofreading and Ivan Verdenik for support regarding statistics.

\section{References}

1. Betts NJ, Vanarsdall RL, Barber HD, Higgins-Barber K, Fonseca RJ. Diagnosis and treatment of transverse maxillary deficiency. Int J Adult Orthodon Orthognath Surg. 1995;10(2):75-96. 
2. Sawchuk D, Currie K, Vich ML, Palomo JM, Flores-Mir C. Diagnostic methods for assessing maxillary skeletal and dental transverse deficiencies: A systematic review. Korean J Orthod. 2016;46(5):331-42.

3. Tosa H, Imai T, Watanabe F, Sumori M, Tsuchida T, Matsuno I, et al. [The clinical study on occurrence of TMJ dysfunction in orthodontic patients]. Nihon Kyosei Shika Gakkai Zasshi. 1990;49(4):341-51.

4. Nie Q, Kanno Z, Xu T, Lin J, Soma K. Clinical study of frontal chewing patterns in various crossbite malocclusions. Am J Orthod Dentofacial Orthop. 2010;138(3):323-9.

5. Angell EH. Treatment of irregularity of permanent adult teeth. Dental Cosmos. 1860;1:540-4.

6. Melsen B. A histological study of the influence of sutural morphology and skeletal maturation on rapid palatal expansion in children. Trans Eur Orthod Soc. 1972:499-507.

7. Revelo B, Fishman LS. Maturational evaluation of ossification of the midpalatal suture. Am J Orthod Dentofacial Orthop. 1994;105(3):288-92.

8. Wehrbein $\mathrm{H}$, Yildizhan F. The mid-palatal suture in young adults. A radiological-histological investigation. Eur J Orthod. 2001;23(2):105-14.

9. Camps-Pereperez I, Guijarro-Martinez R, Peiro-Guijarro MA, Hernandez-Alfaro F. The value of cone beam computed tomography imaging in surgically assisted rapid palatal expansion: a systematic review of the literature. Int J Oral Maxillofac Surg. 2017;46(7):827-38.

10. Nada RM, van Loon B, Maal TJ, Berge SJ, Mostafa YA, Kuijpers-Jagtman AM, et al. Threedimensional evaluation of soft tissue changes in the orofacial region after tooth-borne and boneborne surgically assisted rapid maxillary expansion. Clin Oral Investig. 2013;17(9):2017-24.

11. Magnusson A, Bjerklin K, Kim H, Nilsson P, Marcusson A. Three-dimensional computed tomographic analysis of changes to the external features of the nose after surgically assisted rapid maxillary expansion and orthodontic treatment: a prospective longitudinal study. Am J Orthod Dentofacial Orthop. 2013;144(3):404-13.

12. Nada RM, van Loon B, Schols JG, Maal TJ, de Koning MJ, Mostafa YA, et al. Volumetric changes of the nose and nasal airway 2 years after tooth-borne and bone-borne surgically assisted rapid maxillary expansion. Eur J Oral Sci. 2013;121(5):450-6.

13. Baysal A, Ozturk MA, Sahan AO, Uysal T. Facial soft-tissue changes after rapid maxillary expansion analyzed with 3-dimensional stereophotogrammetry: A randomized, controlled clinical trial. Angle Orthod. 2016;86(6):934-42.

14. Altorkat Y, Khambay BS, McDonald JP, Cross DL, Brocklebank LM, Ju X. Immediate effects of rapid maxillary expansion on the naso-maxillary facial soft tissue using 3D stereophotogrammetry. Surgeon. 2016;14(2):63-8.

15. Kim AJ, Gu D, Chandiramani R, Linjawi I, Deutsch ICK, Allareddy V, et al. Accuracy and reliability of digital craniofacial measurements using a small-format, handheld 3D camera. Orthod Craniofac Res. 2018.

16. Lagravere MO, Major PW, Flores-Mir C. Dental and skeletal changes following surgically assisted rapid maxillary expansion. Int J Oral Maxillofac Surg. 2006;35(6):481-7. 
17. Xi T, Laskowska M, van de Voort N, Ghaeminia H, Pawlak W, Berge S, et al. The effects of surgically assisted rapid maxillary expansion (SARME) on the dental show and chin projection. $\mathrm{J}$ Craniomaxillofac Surg. 2017;45(11):1835-41.

18. Oliveira TFM, Pereira-Filho VA, Gabrielli MFR, Goncales ES, Santos-Pinto A. Effects of surgically assisted rapid maxillary expansion on mandibular position: a three-dimensional study. Prog Orthod. 2017;18(1):22.

19. Alves N, Oliveira TFM, Pereira-Filho VA, Goncales ES, Gabrielli MAC, Passeri LA. Nasolabial changes after two different approaches for surgically assisted rapid maxillary expansion. Int J Oral Maxillofac Surg. 2017;46(9):1088-93.

20. Verdenik $\mathrm{M}$, Ihan Hren $\mathrm{N}$. in three-dimensional soft tissue changes after upper, lower, or both jaw orthognathic surgery in skeletal class III patients. Int J Oral Maxillofac Surg. 2014;43(11):1345-51.

\section{Figures}
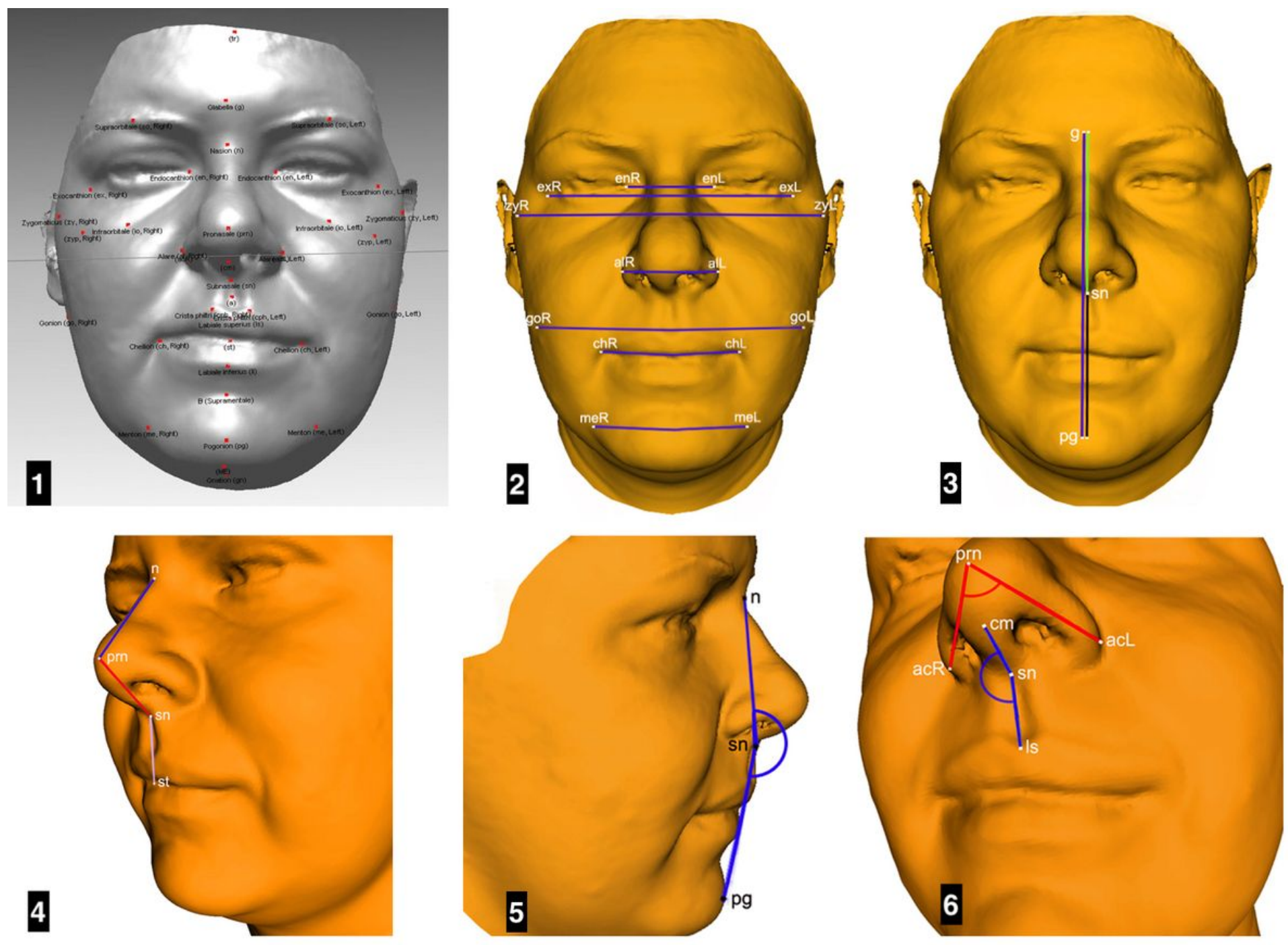

Figure 1 
3D facial image with anthropometric landmarks (1) and selected parameters in the transverse (2), vertical $(3,4)$, and sagittal planes $(5,6)$.

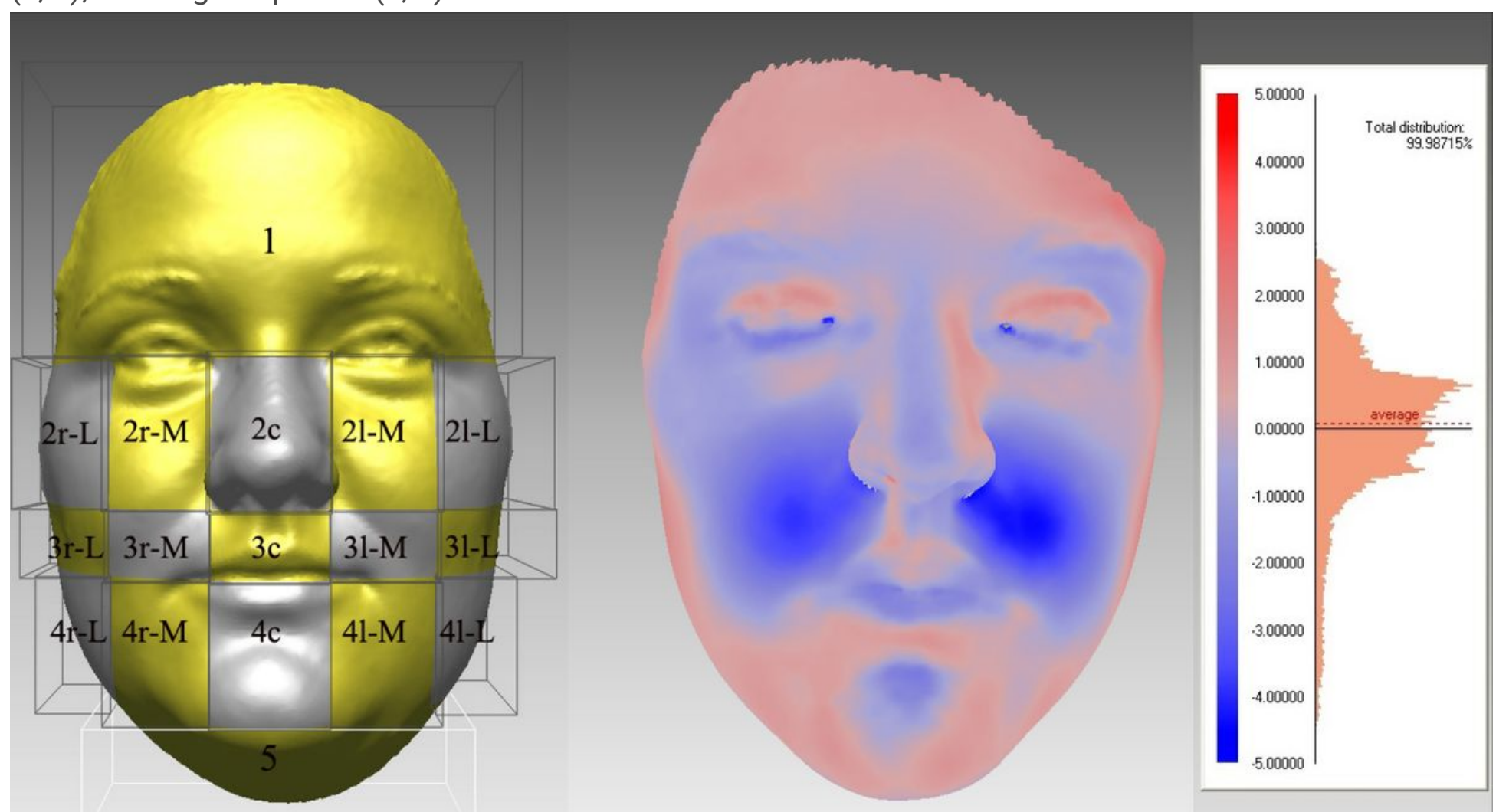

\section{Figure 2}

Left - Facial surface divided into five main areas ( 1 to 5 ) using four horizontal planes. Four vertical planes additionally subdivide areas $2-4$ into the central, medial and lateral regions (r-right, c-central, I-left, Mmedial, L-lateral. Middle - Color map of the superimposed 3D scans, and color histogram on the right, demonstrating the degree of deviation between the pre- and post-operation facial images of one selected patient. The increased blue saturation corresponds to the positive distance, which is most intensively seen in the paranasal area and in the area superior and lateral to the upper lip and the red saturation corresponds to backward changes. 


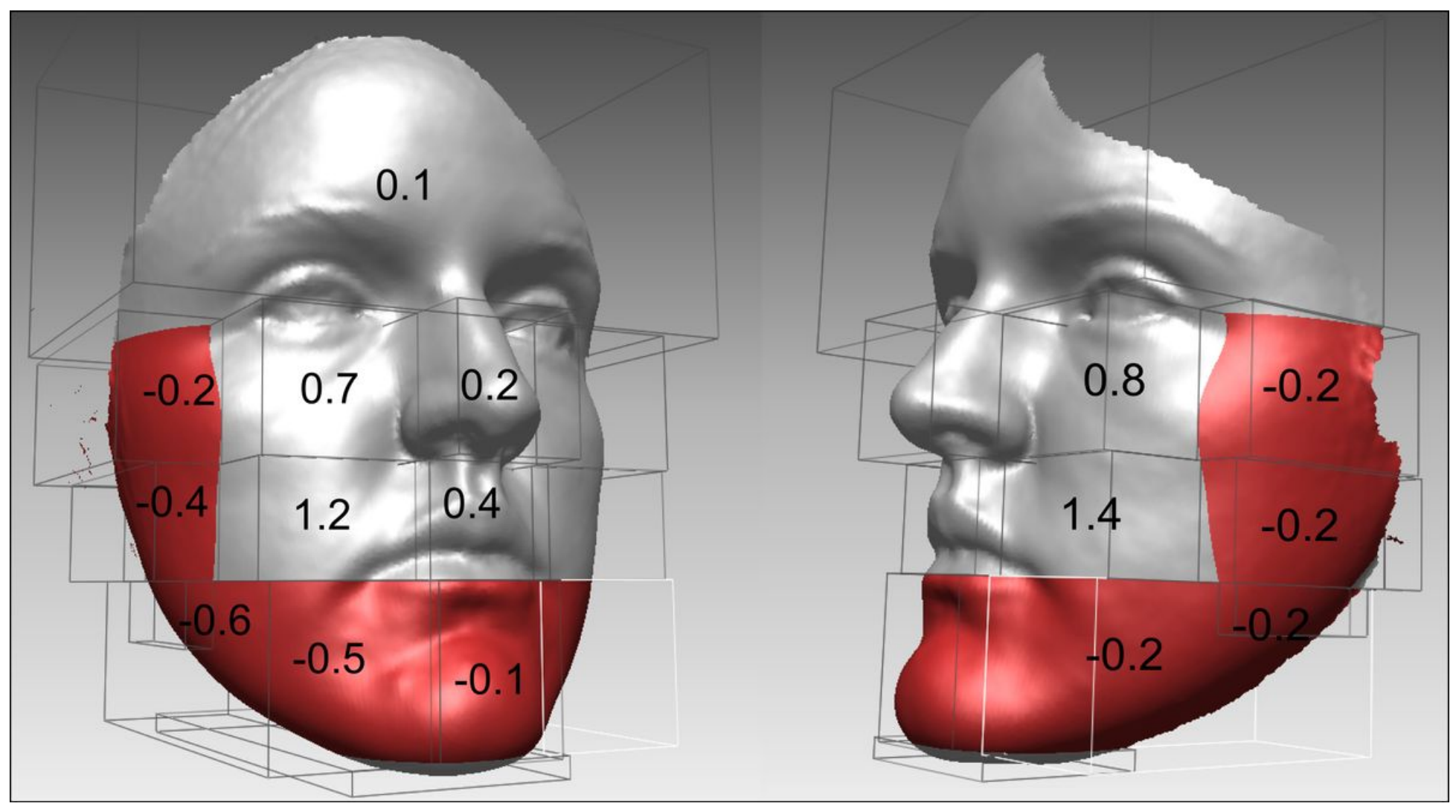

Figure 3

The mean facial differences between the pre- and post-operative scan in the observed regions in $\mathrm{mm}$. The red color presents the areas with backward changes and the grey color the forward changes. 